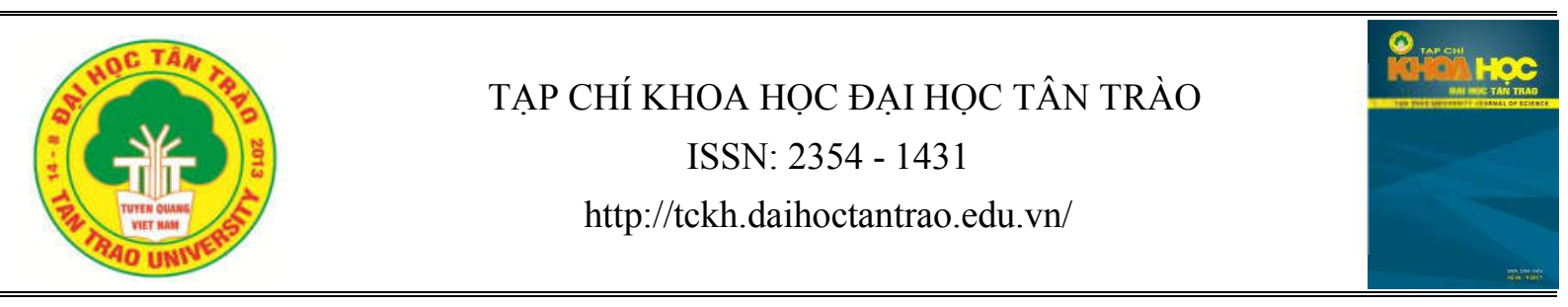

\title{
Nhà nước Đại Cồ Việt tổ chức thực hiện các công trình công cộng
}

Hà Mạh Khoa ${ }^{a^{*}}$

${ }^{a}$ Viện Sủ hoc, Viện Hàn lâm KHXH Việt Nam

*Email: hamanhkhoa@yahoo.com.vn

\section{Thông tin bài viết}

Ngày nhận bài:

$22 / 4 / 2018$

Ngày duyệt đăng:

$12 / 6 / 2018$

Tù khoá:

Đinh Tiên Hoàng, Đại Cồ Việt, Tiền Lê, nhà Lý, Lê Hoàn, sông đào, Thanh Hóa, Ninh Bìn, Nghệ An, Đồng Cổ, Bà Hòa, Kênh Lấm, Kênh Đa Cái.

\section{Tóm tắt}

Những sông đào thời kỳ quốc hiệu Đại Cồ Việt do vua Lê Đại Hành khởi xướng tổ chức thực hiện là những công trình giao thông thuỷ nội địa đầu tiên trong lịch sử nước ta. Sự nghiệp mở đầu vĩ đại đó của thời Tiền Lê đã trở thành phương châm hành động của tất cả các thời Lý, Trần, Lê, Nguyễn. Các thời đại kế tiếp nhau không chỉ luôn khơi đào, nạo vét các dòng sông cũ mà còn liên tục đào thêm các sông mới. Thời Lý, Trần sông đào đã xuất hiện ở đồng bằng Bắc Bộ đến Thanh - Nghệ - Tĩnh... Đến thời Hậu Lê đã rộng khắp dải miền Trung Bộ và đến thời Nguyễn thì sông đào có mặt ở khắp mọi miền đất nước. Các sông đào không chỉ góp phần quan trọng để phát triển kinh tế, văn hóa xã hội mà còn có những đóng góp không nhỏ trong sự nghiệp bảo vệ vững chắc biên giới phía Nam, mở rộng bờ cõi, góp phần quan trọng trong sự nghiệp xây dựng, bảo vệ Tổ quốc trong suôt tiến trình của lịch sử dân tộc.
Từ năm Mậu Thìn (968), Đinh Tiên Hoàng lên ngôi, "đặt quốc hiệu là Đại Cồ Việt"1. Quốc hiệu đó được duy trì đến tháng 10 năm Giáp Ngọ (1054), Lý Thánh tông đổi là "Đại Việt"2. Trong thời gian đó, với quốc hiệu là Đại Cồ Việt dù đứng đầu quốc gia đã có sự chuyển đổi từ dòng họ Đinh - người mở đầu là Đinh Bộ Lĩnh đến dòng họ Lê mở đầu là Lê Hoàn và dòng họ Lý mở đầu là Lý Công Uẩn, nhưng thế và lực của quốc gia không ngừng lớn mạnh. Một trong những minh chứng cho sự phát triển đó của nhà nước Đại Cồ Việt là đã tổ chức thực hiện các công trình công cộng mà tiêu biểu nhất là các công trình đào sông do Lê Đại hành khởi xướng và hoàn thành vào năm 983 . Những con sông đào do nhà nước Đại Cồ Việt tổ chức thực hiện đó không chỉ được tiếp tục khơi đào và mở rộng trong cả nước dưới quốc hiệu Đại Cồ Việt mà dưới quốc hiệu Đại Việt, Việt Nam, Đại Nam, các nhà nước quân chủ vẫn tiếp tục đào lại, mở rông, đào mới các sông trên mọi miền đất nước. Các sông đào không

${ }^{1}$ Đại Việt sủ ký toàn thu (1993), t1, Nxb Khoa học xã hội, Hà Nội, tr 211;

${ }^{2}$ Đại Việt sử ký toàn thu (1993), t1, sđd, tr 270. chỉ góp phần quan trọng để phát triển kinh tế, văn hóa xã hội và còn có những đóng góp không nhỏ trong sự nghiệp bảo vệ vững chắc biên giới phía Nam và mở rộng bờ cõi góp phần quan trọng trong sự nghiệp xây dựng, bảo vệ Tổ quốc trong suôt tiến trình của lịch sử dân tộc.

\section{Những sông đào từ năm 980 đến năm 1009 dưới thời Tiền Lê}

Sau hai năm bằng tất cả các biện pháp từ thuyết phục, vận động, liên kết, hàng phục và dùng sức mạnh quân sự tiến hành đánh dẹp, Đinh Bộ Lĩnh lần lượt thu phục được các sứ quân, chấm dứt tình trạng phân tán cát cứ, thống nhất đất nước. Nhà sử học Lê Văn Hưu đã viết về công lao đó như sau: "Tiên Hoàng nhờ có tài năng sáng suốt hơn người, dũng cảm mưu lược nhất đời, đương lúc nước Việt ta không có chủ, các hùng trưởng cát cứ, một phen cất quân mà mười hai sứ quân phục hết" 3 . Thắng lợi của Đinh Bộ Lĩnh trong quá trình chinh phục các thế lực cát cứ, thể hiện xu thế tập quyền và thống nhất quốc gia là quy luật tất yếu

\footnotetext{
${ }^{3}$ Đại Việt Sử ký toàn thu, (1993), t1, sđd, tr. 154;
} 
của nước ta vào thế kỷ X. Năm Mậu Thìn (968), Đinh Bộ Lĩnh lên ngôi Hoàng đế và cho định đô ở Hoa Lư, đặt quốc hiệu là Đại Cồ Việt. Mùa Đông, tháng Mười năm Kỷ Mão (979), Đinh Tiên Hoàng bị sát hại, Đinh Toản mới 6 tuổi được nối ngôi. Trong thời gian hơn 10 năm, dưới đời vua Đinh Tiên Hoàng và Đinh Toản, nhà nước Đại Cồ Việt do Đinh Tiên Hoàng khởi lập đã tạo dựng nhiều tiền đề quan trọng để xây dựng một nhà nước quan chủ vững mạnh. Nhưng do nhiều nguyên nhân nên chưa có một công trình công cộng nào do nhà nước đứng ra tổ chức thực hiện.

Tháng 7 năm Canh Thìn (980), Lê Hoàn lên ngôi Vua. Triều Tiền Lê do Lê Đại Hành đứng đầu là sự nối tiếp triều Đinh. Lê Đại Hành vẫn định đô ở Hoa Lư, quốc hiệu vẫn là Đại Cồ Việt.

Kế tục sự nghiệp của Vua Đinh Tiên Hoàng, gánh vác trọng trách đứng đầu quốc gia Đại Cồ Việt, Vua Lê Đại Hành đã giữ vững nền độc lập dân tộc, đánh tan quân xâm lược nhà Tống vào năm 981 và kế tiếp sau là "hành quân trị tội Chiêm Thành". Không chỉ có võ công hiển hách, trong sự nghiệp cai trị của mình, Lê Đại Hành còn là một vị "minh quân" trong sự nghiệp phát triển đất nước. Một sự nghiệp chinh phục và cải tạo tự nhiên vĩ đại của cả dân tộc ở thế kỷ $\mathrm{X}$ đến nay vẫn còn nguyên giá trị và gắn liền với tên tuổi vua Lê Đại Hành là tiến hành đào các sông bắt đầu ở đất Thanh Hoá “từ Đồng Cổ đến Bà Hoà”. Với sự kiện đó Lê Đại Hành trở thành Người mở đầu cho sự nghiệp phát triển hệ thống giao thông thuỷ nội địa Việt Nam dưới thời quân chủ thể hiện tầm nhìn chiến lược và phát triển giao thông thủy nội địa trong phát triển kinh tế và bảo vệ Tổ quốc. Các sông đào dưới thời nhà Tiền Lê không chỉ góp phần quan trọng để phát triển kinh tế, văn hóa xã hội và còn có những đóng góp không nhỏ trong sự nghiệp bảo vệ vững chắc biên giới phía Nam và mở rộng bờ cõi góp phần quan trọng trong sự nghiệp xây dựng, bảo vệ Tổ quốc trong suôt tiến trình của lịch sử dân tộc.

\section{1. Đào sông trên đất Thanh Hóa}

Sau khi trừng phạt Champa vì "Trưóc đó vua sai Tù Muc, Ngô Tử Canh sang sú Chiêm Thành, bị người Chiêm bắt giữ", ${ }^{\prime \prime}$ thắng lợi trở về vua Lê Đại Hành cho đào kênh từ núi Đồng Cổ đến sông Bà Hoà. Đây được xem là tuyến đường giao thông thủy nội địa công trình công cộng đầu tiên trong lịch sử Việt Nam do nhà nước tổ chức thực hiện.

\footnotetext{
${ }^{4}$ Đai Việt Sủ ký toàn thur, (1993), t1, sđd, tr 222;
}

Toàn thư chép: "Khi nhà vua đi đánh Chiêm Thành, tù̀ núi Đồng Cổ đến sông Bà Hoà, đường núi hiểm trở khó đi, người ngựa mỏi mệt, đuờng biển thì sóng to khó đi lại, bèn sai đào kênh, đến đây (Quý Mùi - năm 983) thì xong công tu đều lợi","

Đến thế kỷ $X$, đường bộ Thanh Hoá vào phía Nam cũng hiểm trở không kém ra phía Bắc. Đường đi từ Thanh Hoá vào Nghệ An, Hà Tĩnh không thể có đường nào khác ngoài cách đi đường bộ hoặc vượt biển. Trong khi đường bộ thì hoang vu, rậm rạp, đường biển thì bão tố thất thường không chủ động. Đường thuỷ tuy có các sông lớn và các chi lưu, nhưng do các sông đều chảy theo hướng Tây Bắc xuống Đông Nam đã chia cắt các vùng miền và chưa có tuyến giao thông thuỷ nội địa theo hướng Bắc - Nam.

Đồng Cổ nằm ở hữu ngạn sông Mã, thuộc xã Yên Thọ, huyện Yên Định, tỉnh Thanh Hoá ngày nay. Sông Bà Hoà ở phía cực Nam tỉnh Thanh Hoá, thuộc xã Tân Trường, huyện Tĩnh Gia giáp huyện Quỳnh Lưu, tỉnh Nghệ An. Sông Bà Hoà đổ ra cửa Lạch Bạng thuộc xã Hải Thanh, huyện Tĩnh Gia. Lê Đại Hành hiểu rõ địa hình vùng đất này và biết rõ hệ thống sông ngòi ở đây chảy theo hướng Tây Bắc - Đông Nam. Vì vậy, Lê Đại Hành đã cho tiến hành đào sông nối sông Mã ở Bắc Thanh Hoá với sông Bà Hoà ở Nam Thanh Hoá Bắc Nghệ An. Nhưng điều đó không có nghĩa là đào một con sông hoàn toàn mới. Lê Hoàn đã tận dụng những chi lưu nhỏ của các lớn như: sông Mã, sông Lương (Chu), sông Vạy (Hoàng), sông Yên, sông Bà Hòa...khơi sâu, nắn thẳng và đào một số đoạn cần thiết để hình thành một tuyến giao thông thuỷ nội địa nối liền sông Mã - sông Cầu Chày - sông Lương (Chu)- sông Vạy (Hoàng) - sông Yên- sông Cầu Hang- sông Bà Hòa. Đây là tuyến giao thông thủy nội địa thuận tiện nhất từ Bắc đến Nam Thanh Hoá.

Mười năm sau khi đào sông từ Đồng Cổ đến Bà Hoà, Năm 992, Tháng 8 , mùa thu, Lê Đại Hành sai phụ quốc Ngô Tử An đem ba vạn người mở đường bộ từ cửa biển Nam Giới đến châu Địa Lý nước Chiêm Thành. Gia phả họ Ngô chép: Ngô Tử Án là con trai Ngô Xương Sắc, ông làm quan triều Tiền Lê Lý, được Lê Đại Hành sai đào vét các kênh sông từ Yên Định đến Tĩnh Gia... tiếp tục đào sông nối từ kênh Bà Hòa vào phía Nam.

\section{2. Đào sông trên đất Nghệ An}

Sau khi đào sông từ Đồng Cổ đến Bà Hòa và thấy được tác dụng lớn lao của nó, Lê Đại Hành và các vua

\footnotetext{
${ }^{5}$ Đại Việt Sủ ký toàn thu, (1993), t1, sđd, tr. 222.
} 
nhà Tiền Lê tiếp tục cho khơi đào các sông trên đất Nghệ An.

Từ sông Bà Hòa (thuộc xã Tân Trường, Tĩnh Gia, Thanh Hoá), Lê Đại Hành cho đào kênh Xước nối theo hướng Nam, men theo chân núi Xước nối với sông Hoàng Mai. Đọa kênh từ Sòi Trẹ (xã Quỳnh Lộc, huyện Quỳnh Lưu, tỉnh Nghệ An) đổ vào sông Hoàng Mai ở phía Bắc làng Ngọc Huy (nay thuộc khối 1, phường Mai Hùng, Thị xã Hoàng Mai và gọi là Kênh Son. Từ Ngọc Huy, kênh chảy qua các xã vùng Bãi Ngang gọi là Kênh Mơ (còn gọi là kênh Mai Giang, kênh Ngọc Để) rồi đổ ra Lạch Quèn (nay thuộc địa phận xã Tiến Thủy (Quỳnh Tiến), và xã Quỳnh Thuận (huyện Quỳnh Lưu). Dòng kênh này men theo dòng nước chảy là khe Nước Lạnh, là đường ranh giới phía Nam Thanh Hoá, Bắc Nghệ An, thuộc huyện Quỳnh Lưu.

Kênh Sắt (Từ xã Diễn An, huyện Diễn Châu và đến huyện Nghi Lộc hiện nay). Đây cũng là con kênh gặp rất nhiều gian nan khi đào do có một đoạn đi qua mỏ sắt ở núi Sắt chứa nhiều đá quặng rắn.

Kênh Sắt (nay thuộc Diễn Châu) ngày nay còn dấu vết một chiếc ghế đá tạc trong hang sát với kênh Sắt. Chỗ tựa có ba chữ "Thuỷ Thạch Tiên", trên vách đá có bài thơ. Tương truyền ghế đá và bài thư của Ngô Tử Án ${ }^{6}$. Đây cũng là con kênh gặp rất nhiều gian nan khi đào do có một đoạn đi qua mỏ sắt ở núi Sắt chứa nhiều đá quặng rắn. Sách Đồng Khánh địa $d u$ chi phần Nghệ An tỉnh, chép về đoạn kênh này như sau: "Một dòng kênh nhỏ, từ thôn Thổ Hậu qua xã Phú Hậu, tổng Quan Trung, xã Nho Lâm, tổng Cao Xá, (kênh Sắt là tên gọi đoạn kênh nhà Lê chảy qua Truông Sắt thuộc xã Diễn An, huyện Diễn Châu và huyện Nghi Lộc hiện nay)... ngoằn ngoèo chảy đến kênh Sắt bến đò sông Cấm rồi hợp dòng đổ xuống cửa biển, dài 9 dặm, rộng 7 trượng, triều lên sâu 5 thước, triều xuống sâu 3 thước"”?

Hai mươi năm sau khi đào sông từ Đồng Cổ đến Bà Hoà, trên đất Nghệ An, năm “Quý Mão (1003), Lê Đại Hành đi Hoan Châu (Nghệ An) sai đào kênh Đa Cái” " (nay thuộc huyện Hưng Nguyên, tỉnh Nghệ An). Kênh Đa Cái tức là kênh nối kênh Sắt ở khu vực huyện Nghi Lộc với sông Lam. Như vậy dưới thời

\footnotetext{
${ }^{6}$ Quốc sử quán triều Nguyễn (1998), Khâm định Việt sủ thông giám cuong muc, t1, Nxb Giáo dục, tr. 151

${ }^{7}$ Đồng Khánh địa du chí (2003), Nxb Thế giới, Hà Nội, tr 33;

${ }^{8}$ Đại Việt Sủ ký toàn thur, (1993), t1, sđd, tr. 230;
}

Tiền Lê từ sông Mã ở Thanh Hóa đến sông Lam ở Nghệ An ngoài tuyến đường bộ và đường biển đã có một tuyến đường thuỷ nội địa an toàn, thuận tiện 9 .

Các kênh đào thời nhà Tiền Lê đã nối thông với các sông tự nhiên thành một hệ thống đường thuỷ nội địa thông suốt từ Đồng Cổ (Thanh Hóa) đến hạ lưu sông Lam. Thuyền vận tải có thể từ các bến cảng thuộc Bắc Hà Tĩnh có thể theo các sông này đi khắp các vùng thuộc Nghệ An, Thanh Hóa ra đến Kinh đô Hoa Lư và ra phía Bắc.

Trong vòng 30 tồn tại vương triều Tiền Lê, hệ thống kênh nhà Lê do Lê Đại hành chỉ đạo khai mở và các vua sau tiếp tục thực hiện đã nối với các hệ thống sông có sẵn ở phía Nam Thanh Hóa vào tới Nghệ An đã mang lại giá trị vô cùng to lớn cho các đợt Nam tiến của nhà nước Đại Cồ Việt cũng như cho các triều đại sau.

\section{Những sông đào từ năm 1010 đến năm 1054 dưới thò̀i $L y ́$}

Năm 1010, nhà Lý thay nhà Tiền Lê trị vì đất nước và dời kinh đô từ Hoa Lư ra Thăng Long. Trong suốt thời gian tồn tại từ 1010 đến 1225 , theo số liệu được ghi trong Đại Việt sủ ký toàn thu, nhà Lý đã tổ chức lực lượng đào sông trong cả nước 4 lần thuộc các tỉnh Thanh Hoá, Bắc Ninh ${ }^{10}$, Ninh Bình và Hà Nội ${ }^{11}$ ngày nay. Tuy nhiên dưới quốc hiệu Đại Cồ Việt dưới đời vua Lý Thái tông đã cho tiến hành đào các sông như sau:

\section{1. Đào sông Đan Nãi}

Năm Kỷ Tỵ (1029), đào sông Đan Nãi. Sông Đan Nãi là sông mà Lê Hoàn đã khơi đào xong năm 983, đi qua địa phận huyện Yên Định và Thọ Xuân tỉnh Thanh Hoá.

Sách Đại Việt sử toàn thu ghi: "Giáp Đan Nãi ${ }^{12}{ }^{\circ}$. châu Ái làm phản, mùa Hạ, tháng tu (1029) vua đi đánh giáp Đan Nãi, cho Đông Cung thái tủ giám quốc. Khi đánh được giáp Đan Nãi rồi, sai trung sút đốc suất người Đan Nãi đào kênh Đan Nãi”"13. Qua đó ta thấy, chỉ sau một năm lên ngôi, Lý Thái tông đã về

\footnotetext{
${ }^{9}$ Hà Mạnh Khoa (2000), Sông đào ở Thanh Hóa tù thế kỷ X đến thế kỷ XIX, Nxb KHXH, tr.107;

${ }^{10}$ Năm Kỷ Sửu (1089), đào sông Lãnh Kinh trong Du địa chí, Nguyễn Trãi chú rằng: "Đời Lý sai đào sông Bình Lố, tù Lãnh Kinh đến Bình Lố, thông với Bình Than để tiện đi lại ở Thái Nguyên. Đây là sông thuộc vùng Thị Cầu, tỉnh Bắc Ninh;

${ }^{11}$ Năm Nhâm Tý (1192), đào sông Tô Lịch ở kinh thành Thăng Long;

${ }^{12}$ Giáp Đan Nãi nay thuộc huyện Yên Đinh, tỉnh Thanh Hóa;

${ }^{13}$ Đại Việt Sủ ký toàn thur, (1993), t1, sđd, tr 259;
} 
vùng đất này. Đây là nơi có đền thờ thần Đồng cổ (trống đồng) rất linh thiêng, theo Đại Nam nhất thống chi chép: "Vua Lý Thái Tổ đi đánh Chiêm Thành, đóng quân ở xã Truờng Yên, đêm mong thấy người mặc áo giáp nói: Tôi là thần núi Đồng Cổlu, xin đi theo đánh giặc lâp công. Khi dẹp được Chiêm Thành, nhà vua bèn lập đền thò̀ ở phía Bắc thành Thăng Long ${ }^{15}$. Lúc Thái Tông lên ngôi, đêm nằm mộng thấy thần báo cho biết việc ba vioong gây biến loạn, sau khi dẹp, nhà vua khen có công, phong là Thiên ha chủ minh chi thần" ${ }^{\prime 6}$ và Lý Thái Tông quy định hàng năm tất cả con cháu họ Lý và các đại thần trong triều chỉnh đốn đội ngũ, treo gươm giáo trước thần vị, cùng nhau uống máu ăn thề: "Làm con bất hiếu, làm tôi bất trung xin thần minh giết chết" Qua đó ta thấy vùng Đan Nãi này có ảnh hưởng đối với các vua nhà Lý như thế nảo?

Vậy đào sông Đan Nãi là đào sông nào trên khu vực này? Vào năm 983, sau khi đi đánh Chiêm Thành về, Lê Đại Hành thấy: "Đường núi hiểm trở khó đi, nguoòi ngưa mói mệt, đuoòng biển thì sóng to khó đi, bèn sai ngườ đào sông từ núi Đồng Cổ đến sông Bà $H o ̀ a^{, 18}$. Theo chúng tôi sông Đan Nãi được đào vào ở thời Lý vẫn là con sông mà Lê Đại Hành đã đào nối từ khu vực đền Đồng Cổ đến sông Lương (sông $\mathrm{Chu}$ ). Ngoài lực lượng của nhà nước cử đến, nhân dân trong vùng cũng tích cực tham gia. Thần phả đền thờ Thành Hoàng "Kim kê chi thần" thôn Ngọc Quang, xã Xuân Vinh, huyện Thọ Xuân, còn ghi như sau: "Thần họ Kim tên là Thí Võ làm quan trung uý đòi vua Lý Thánh Tông. Sau về làng nghỉ, ông thấy dân làng bi cảnh lũ lut rất khổ cục bèn tư bỏ tiền ra và quyên thêm để đào con ngòi cho nước tiêu chảy ra sông. Tù đó dân làng được yên ổn trong mùa lũ sau khi mất đươc vua khen là nguoòi trung với nước, lọi cho dân và phong là Kim Kê, cho dân lập đền thờ" ${ }^{19}$.

Như vậy đến thời Lý vùng Đan Nê không chỉ là nơi có đền thờ trống đồng linh thiêng của cả nước, vẫn là điểm hội tụ của giao thông thuỷ bộ từ Bắc vào

\footnotetext{
${ }^{14}$ Đền Đồng Cổ nay ở xã Yên Thọ, huyện Yên Định, tỉnh Thanh Hóa;

${ }^{15}$ Đền thờ này nay ở phường Yên Thái, quận Ba Đình, Hà Nội.

${ }^{16}$ Đại Nam nhất thống chí, (1970), t2, Nxb Thuận Hóa - Huế, tr 253 ;

${ }^{17}$ Đại Việt Sử ký toàn thu, (1993), t1, sđd, tr 255;

${ }^{18}$ Đai Việt Sử ký toàn thu, (1993), t1, sđd, tr 219;

${ }^{19}$ Trần Văn Thịnh (1995), Danh Sĩ Thanh Hoá và việc học thờ xua, Nxb Thanh Hoá, tr 20;
}

Thanh Hoá, điểm khởi đầu của con đường giao thông thuỷ chiến lược từ Thanh Hoá vào Nam.

\subsection{Tiếp tục đào sông Bà Hòa}

Từ thời Tiền Lê, vào năm 983 Lê Đại hành đã cho đào kênh từ núi Đồng Cổ (Yên Định - Thanh Hóa) đến sông Bà Hòa (Tĩnh Gia - Thanh Hóa)... Từ đó sông Bà Hòa trở thành con đường giao thông thủy quan trọng từ Nam Thanh và Bắc Nghệ. Đến thời Lý vào năm 1041, khi Lý Thái Tông có ý định đánh Chiêm Thành, đã giao cho Lý Nhật Quang ${ }^{20}$ làm một "hoành doanh" dọc theo sông Bà Hòa. "Hoành doanh" ở vào một vị trí hiểm trở, kiên cố. Bốn mặt có hào sâu, lũy cao, còn ở trong là nền đất rộng có thể chứa được ba, bốn vạn quân lưu thủ, ngoài ra lại có các kho tàng chứa vật dụng, và lương thực thì dự trữ đủ dùng trong ba năm liền. Xung quanh đặt các điếm canh, ngày đêm tổ chức tuần tra canh phòng cẩn mật.

Khi được cử cai quản vùng Nghệ An, Lý Nhật Quang không chỉ lập một "hoành doanh" ở đây mà còn cho đào sông từ cực Nam Thanh Hoá qua Diễn Châu đến bờ Bắc sông Lam, tạo thành một tuyền giao thông thuỷ thông suốt từ sông Bà Hoà (Tĩnh Gia Thanh Hoá ) đến sông Lam (Nghệ An). Ba năm sau (1044) Lý Thái Tông cất đại quân đi đánh Chiêm Thành và khi chiến thắng dẫn quân trở về tới hoành doanh Bà Hòa thì vua Lý Thái Tông nghỉ lại. Nhật Quang đón tiếp nhà vua và sắp xếp nơi ăn chốn nghỉ cho quân sĩ đầy đủ, chu đáo. Nhà vua thấy kho tàng cùng nhiều nơi khác, sắp đặt gọn gàng, xem xét các giấy tờ sổ sách, thấy ghi chép cẩn thận, rõ ràng đâu ra đấy hết lời khen ngợi. Nhà vua rất hài lòng, thăng cho Lý Nhật Quang từ tước hầu lên tước vương, lại cho cai quản thêm một lộ mới cùng với châu Nghệ An.

\section{3. Đào kênh Lẫm}

Năm Tân Mão (1051), mùa đông, tháng11, đào kênh Lẫm ${ }^{21}$. Đây là đoạn sông đào nối liền sông Vân Sàng với cửa Tạc khẩu đi vào Thanh Hoá tránh cửa biển Thần Phù.

Sông Vân Sàng: "Ỏ phái Nam huyện Yên Khánh, nước song từ ngã ba Non nước chảy qua ngã ba Vũ Lâm (tục gọi là kênh Khát, ngã ba Yên Đăng và ngã ba Yên Phú thuộc huyện Yên Khánh lại chảy qua ngã ba Liên Trì thuộc huyện Yên Mô đến địa phận xã Trinh Nữ gọi là song Trinh Nữ, đến ngã ba Hổ lại

\footnotetext{
${ }^{20}$ Lý Nhật Quang là con trai thứ 8 của Thái Tổ Lý Công Uẩn, hiệu là Bát Lang hoàng tử, mất năm Đinh Dậu (1057).

${ }^{21}$ Đại Việt Sủ ký toàn thu, (1993), t1, sđd, tr 269;
} 
chảy qua núi Ngọc Thỏ đến ngã ba Bồ Xuyên đổ vào cửa sông Thần Phù (trước là cửa biển Thần Phù, đấy là chi lưu tắt. Còn từ sông Bạch Hổ (tức hạ lưu sông Trinh Nữ) chảy về phía Đông Nam đổ vào địa phận sông càn, gọi là sông Càn (trước là cửa Càn), đấy là phân lưu"'22.

Đại Nam nhất thống chí chép về kênh Lẫm như sau: "kênh Lẫm ở địa phận xã Thần Phù, Phù Sa và Ngọc Lâm huyện Yên Mô, nguyên kênh truớc này thong với song Hổ Hà. Hồ Quý Ly tải đá lấp đi nay thành đất bằng, chỉ còn là đất bằng, tuc gọi là đầm Lẫm. Bài tho qua biển Thần Phù của Lê Thánh tong có câu "Chuoong Hoàng trọng tái điền hà thạch" nghĩa là tải đá khó nhọc để lấp sông tức là chổ này ",23.

Kênh Lẫm bắt đầu tư ngã ba Đức Hậu (xóm Trung Đồng xã Yên Nhân) chảy qua địa phận các xã Yên Từ, Yên Nhân, Yên Mạc, Yên Mỹ, Yên Thái, Yên Lâm chảy ra biển qua cửa Càn. Lòng sông hẹp và nông, dài khoảng $16 \mathrm{~km}$. Ngoài nhiệm vụ tưới tiêu cho sản xuất nông nghiệp đây còn là đường giao thông thuỷ quan trọng từ Ninh Bình vào Thanh Hoá.

Từ những giá trị của các kênh đào thời tiền Lê, thời Lý trong những năm dưới quốc hiệu Đại Cồ Việt khi quốc hiệu mới là Đại Việt các Vua nhà Lý vẫn tiếp tục đào các sông trong cả nước. Các sông đào tiêu biểu đó là đào sông Lãnh Kinh "Năm Kỷ Sửu (1089), đào sông Lãnh Kinh”. Trong $D u$ địa chí, Nguyễn Trãi chú rằng: "Đời Lý sai đào sông Bình Lỗ, tù Lãnh Kinh đến Bình Lỗ, thông với Bình Than để tiện đi lại ở Thái Nguyên "24. Đây là sông thuộc vùng Thị Cầu, tỉnh Bắc Ninh. Và đến năm Nhâm Tý (1192), đào sông Tô Lịch ở kinh thành Thăng Long ${ }^{25}$.

\section{Một vài nhận xét}

Trong công cuộc chinh phục và cải tạo tự nhiên để tồn tại và phát triển, từ những bài học kinh nghiệm tận dụng điều kiện tự nhiên để trồng trọt "dẫn thuỷ nhập điền" đơn giản, cư dân trong các làng xã đã tiến lên chung sức, chung lòng khơi đào, nạo vét những dòng sông tự nhiên tạo ra để phục vụ cho sản xuất và đời sống. Từ đó hình thành những đường giao thông, mở rộng giao lưu, thắt chặt tình đoàn kết giữa các vùng, các miền trong đại gia đình dân tộc Việt Nam. Sông

\footnotetext{
${ }^{22}$ Quốc sử quán nhà Nguyễn (2006), Đại Nam nhất thống chí, tập 3, Nxb Thuận Hóa - Huế, tr 302;

${ }^{23}$ Quốc sử quán nhà Nguyễn (2006), Đại Nam nhất thống chí, tập 3, Nxb Thuận Hóa, tr 304;

${ }^{24}$ Đại Việt Sử ký toàn thu, (1993), t1, sđd, tr 282;

${ }^{25}$ Dại Việt Sử ký toàn thur, (1993), t1, sđd, tr 330.
}

đào từ Thanh Hóa và các tỉnh Nghệ An... ở thời kỳ quốc hiệu Đại Cồ Việt do Lê Đại Hành khởi xướng tổ chức thực hiện là con đường giao thông thuỷ nội địa đầu tiên của nước ta. Con đường đó đã đóng góp không nhỏ vào sự nghiệp bảo vệ vững chắc và mở mang bờ cõi phía Nam và còn thúc đẩy sự phát triển kinh tế xã hội của khu vực Băc Trung bộ trong suốt tiến trình đi lên của lịch sử dân tộc.

Lê Đại Hành là vị vua đầu tiên của nhà nước độc lập tự chủ tổ chức đào sông. Sự nghiệp mở đầu vĩ đại đó của thời Tiền Lê đã trở thành phương châm hành động của tất cả các thời Lý, Trần, Lê, Nguyễn. Các thời đại kế tiếp nhau không chỉ luôn khơi đào, nạo vét các dòng sông cũ mà còn liên tục đào thêm các sông mới. Từ con sông đào do Lê Đại Hành đầu tiên đào trên đất Thanh Hoá thời Tiền Lê, đến thời Lý, Trần sông đào đã xuất hiện ở đồng bằng Bắc Bộ đến Thanh - Nghệ - Tĩnh... Đến thời Hậu Lê đã rộng khắp dải miền Trung Bộ và đến thời Nguyễn thì sông đào có mặt ở khắp mọi miền đất nước.

Những con sông đào đã nối mọi miền đất nước lại gần nhau hơn, biến những vùng hoang vu, hẻo lánh thành nơi trù phú, những pháo đài bất khả xâm phạm trong các cuộc kháng chiến bảo vệ nền độc lập, tự chủ của Tổ quốc, bảo tồn và phát triển bản sắc văn hoá dân tộc. Có thể nói những con sông đào đã góp phần không nhỏ đưa đất nước và dân tộc Việt Nam trở thành một nước có vị trí quan trọng trong khu vực.

Trải qua nhiều thế hệ tiến hành đào sông, trình độ khoa học, kỹ thuật cụ thể là trị thuỷ, thuỷ nông của nhân dân ta đã trở thành nền khoa học dân gian mà các nhà khoa học châu Âu sau này phải khâm phục. Kỹ sư Đờtétxăng đã viết: "Về kỹ thuật tưới nước vào các miền khô khan và tháo nước ở các miền đọng, người Việt Nam là một bậc thầy. Không có sự cực nhọc nào làm cho họ quản ngại. Để gặt được hạt lúa, biểu hiện cho sự phồn thịnh, những công cuộc đào ngòi dẫn nước đã được thi hành. Các kỹ sư thời nay của ta (Pháp) cũng phải kinh ngạc" .

Sông đào thời kỳ mang quốc hiệu Đại Cồ Việt cùng truyền thống yêu nước của toàn dân tộc đã trở thành sức mạnh góp phần quan trọng để bảo vệ và mở mang lãnh thổ đất nước trong thời kỳ trung đại và trong kháng chiến chống Pháp và chống Mỹ những dòng sông đó đã trở thành huyền thoại trong sự nghiệp thống nhất Tổ quốc.

Qua thời gian và những biến động lịch sử, một số sông đào ngày nay không còn. Nhưng những dòng 
sông còn lại vẫn phát huy tác dụng tốt trên các mặt giao thông, thuỷ lợi, du lịch, an ninh quốc phòng, môi trường... Một số nơi do nhận thức và quá trình đô thị hoá đã san lấp các sông đào, vô tình tự hủy bỏ những kỳ tích của các thế hệ trước. Do đó, việc duy trì, bảo vệ, khơi sâu, mở rộng các sông đào không chỉ chúng ta giữ gìn tài sản vô giá của cha ông để lại mà còn góp phần làm cho đất nước trong thời kỳ Công nghiệp hoá - Hiện đại hoá càng giàu, đẹp hơn.

Dưới thời kỳ mang quốc hiệu Đại Cồ Việt, các sông đào đó được các triều đại kế tiếp, tiếp tục khơi đào và mở rộng là một trong những minh chứng về sự lớn mạnh của dân tộc trong quá trình xây dựng, bảo vệ và phát triển đất nước thời Trung đại thể hiện vai trò và vị trí cũng như trách nhiệm của nhà nước trong việc tổ chức và thức hiện các công trình công cộng. Tù̀ trong lịch sử đến hiện tại cũng như tương lai, các dòng sông đó luôn đồng hành cùng cả nước trên con đường đổi mới và phát triển.

\section{TÀI LIỆU THAM KHẢO}

1. Đại Việt sủ ký toàn thu (1993), t1, Nxb Khoa học xã hội, Hà Nội, tr 211;

2. Quốc sử quán triều Nguyễn (1998), Khâm định Việt sử thông giám cuơng mục, Nxb Giáo dục;

3. Đồng Khánh địa du chí (2003), Nxb Thế giới, Hà Nội;

4. Hà Mạnh Khoa (2000), Sông đào ở Thanh Hóa tù thế kỷ X đến thế kỷ XIX, Nxb Khoa học xã hội;

5. Đại Nam nhất thống chí (1970), Nxb Thuận Hóa;

6. Quốc sử quán nhà Nguyễn (2006), Đại Nam nhất thống chí, Nxb Thuận Hóa.

\section{Dai Co Viet state carried out public constructions}

Ha Manh Khoa

\section{Article info}

Recieved:

22/4/2018

Accepted:

$12 / 6 / 2018$

Keywords:

Dinh Tien Hoang, Dai Co Viet, first Le, Ly dynasty, Le Hoan, channel, Thanh Hoa, Ninh Binh, Nghe An, Dong Co, Lam Channel, Da Cai Channel.

\begin{abstract}
The channels in Dai Co Viet Period were carried out by King Le Dai Hanh which were the first inland waterway in our country's history. The great beginning of first Le has become motto of action of all Ly, Tran, Le, Nguyen dynasties. Successive eras not only enlarged and dredged old rivers but also dug new rivers. The Ly dynasty and then the Tran dynasty channels appeared in the Northern Delta to Thanh - Nghe - Tinh. By the end of Le dynasty, channels were widespread throughout the middle of Vietnam, and to the Nguyen dynasty, channels were found in all parts of the country. The channels not only contributes importance to socio-economic developmentbut also be a great contribution to the firmly protect the southern border, expanding the border, making an important contribution to the cause of national construction and defense throughout the history of the nation.
\end{abstract}

